\title{
Research on Green Packaging Design of Ceramic Online Shopping
}

\author{
Cui Dong ${ }^{1, a^{*}}$, Shuiying $\mathrm{He}^{2, \mathrm{~b}}$ \\ ${ }^{1}$ School of Art and Design, Jingdezhen Ceramic Institute, Jingdezhen , 333403,China \\ ${ }^{2}$ Department of Art Design ,Shanghai Industry and Commerce Foreign \\ Language College, Shanghai , 201399,China \\ aaminy530@163.com, $52134328 @ q q . c o m$
}

\begin{abstract}
Keywords: online shopping, ceramic packaging, packaging design, green design
Abstract. With the rapid development of information technology, the popular online shopping came into being, which have lead to a huge number of online shopping packaging waste, and become an important source of environmental pollution in the world. In this paper, the present situation and main problems of online ceramic packing and the importance in the green packaging design of online shopping ceramic products are put forward. On the basis of packaging design in Jingdezhen, the methods of green design of ceramic packaging online shopping are discussed from some aspects, such as the packaging structure, function, form, visual identity and materials, which indicate the direction of sustainable development of online ceramic packaging.
\end{abstract}

\section{Introduction}

With the deep development of information technology, on the basis of Internet technology, the global e-commerce has just experienced more than ten years from birth to today. It had far beyond people's imagination that its influences on human's lifestyle and the economic development. It is an integral part in people's lives that we enjoy online shopping, thus online packaging industries also have great development. Compared with other products, the ceramic in Jingdezhen is a kind of fragile, which was demanded strongly for the packaging in the process of sales and transport. At present, the development of online ceramic packaging was lagged behind and there is not discriminated between the online ceramic packing and entity ceramic packing. The green packaging designed for ceramic online shopping is to be put forward. Using the green packaging to gradually replace the traditional E-Commerce packaging could reduce the cost and the pollution of environment, and meanwhile improve the protection. It would be beneficial for the sustainable development of economy, and could provide ideal packaging solution for the future E-Commerce packaging.

\section{The Present Condition of Online Ceramic Packaging}

The Excessive Packaging Phenomenon. Take Jingdezhen for example, the forms of ceramic packaging in the market are divided into different corrugated box packing and honeycomb paperboard cushions. As for the relatively high-grade ceramic packing, many packaging enterprises usually use the material such as wood, paper, bamboo, composite materials, etc. Some ceramic packaging was added by the brocade fabric, and was used by the color paper to increase its visual effect, which will strengthen the decorative effect and improve the product added value. They also use cartons with some other cushion materials such as newspapers and foams to protect the tablets during shipping, and before transport, the logistics corporation have to nail timber 
frames for large size ceramic products such as ceramic tableware set and tea set to prevent porcelain be collided. Firstly, the packages wrapped in layers can increase the porcelain's quality, volume and the transporting cost. Secondly, it will spend a great deal of manpower, material resources and financial resources on the disposal of packaging waste, resulting in environmental pressures and a huge waste of social energy resources.

The Poor Conveniences. The convenience of online shopping packaging is reflected in two aspects, the one is whether the courier package products simply, the two is whether the consumer open the packaging easily. For courier companies, the packaging process of the fragile product have to spend a lot of human resources, and it is also a huge project to open express packages: First of all, we need to open box by tearing masking tape, but also remove corrugated paper, plastic foam cushioning materials, open the plastic bubble packing heavy parcels, and finally to see the products. Therefore, the function design of this kind of packaging is unreasonable and poor convenience.

The Weak Packing Recognition. The packaging enterprises do not offer targeted design for ceramic packaging and the character is so blurred that it is difficult to identify, since the product packaging does not correspond to the products. Take Some tea set packaging for example, we can only obtain identifying information through the unified text about "the under glaze color porcelain" that marked on the corrugated packaging, barely seeing any trace of a porcelain tea sets and products under the shaft of the packaging.

The Unrecyclable Packaging. According to China's Ministry of Commerce statistics, social total retail sales of consumer goods in domestic consumption market is 26.2 trillion RMB in 2014, in which e-commerce logistics package is more than 14 billion RMB, while the cost of packaging is to reach 1.5 billion RMB. The ceramic package of online shopping is thrown away when it reach consumer's home, which is the main ingredients of urban garbage. And it is difficult to decompose and recycle the packaging materials. In this context, the huge amount of packaging waste has caused a huge threat our environment.

\section{The Necessity and Feasibility to Ceramic Green Packaging Design}

Green packaging, which is called "Ecological packaging", is a kind of packing that can Make use of resource for purpose of well and justify, ensure people's health and safety, maintain the balance of ecological environment in the whole process of design, production, use, circulation, and waste recycling. There are a lot of problems in China's ceramic packaging online shopping, including the waste of resources and the destruction of the environment, while large online ceramic industry, along with huge ceramic packaging industry, has produced large quantities of packaging "pollution" in the era of e-commerce. Thus it is particularly important for the ceramic packing industry to achieve the goal of ecological and green packaging design. For one thing, it is one of the major problems of the human in the 21 st century that how to keep the green and sustainable development of ecological environment, and green packaging design can help to promote the ecological development of Chinese ceramic packaging industry, to improve the quality of ceramic network sales, guide the ceramic packaging enterprises to green design, which will speed up the development of ceramic industry. For another, the packaging rubbishes become a serious problem we cannot ignore. If you can take into account the various aspects of online ceramic packaging in green design, and arouse people's awareness of environmental protection and green healthy lifestyle through the design concept, it will solve the problem of online shopping environment pollution effectively, maximize the guarantee of social energy saving, and play a far-reaching significance to the economic development of the country as well as ceramic producing areas. 


\section{The Methods of Green Design on Ceramic Packaging}

To Optimize Design Structure. There are various of ceramic products full - featured. The main classes of porcelain are art appreciation porcelain, household porcelain, sanitary ware and building ceramic products, and household porcelain can be divided by use of tableware, tea, coffee, bottle, stationery, cans, and other jars. Therefore, the packing form and the specification are so complicated that the costs become increasingly higher in the design, storage and logistics management. The best way for online ceramic green packaging is to optimize design structure. First of all, whether it is a single product or suite of products, we can use structure of universal design, according to external dimensions and weight of ceramic products. And we can set up a hole in the interior for a single product in advance, with the text pattern recognition in the external. What is more, we can also use a series of packaging design to create a unified style of packaging for different kinds of ceramic brand, with a similar and unluxurious pattern and color. Regardless of product type, size and shape, by using the same form, even the same specification of packaging, to unify structure form on different ceramic product packaging, to save material resources and even save some expenses.

To Design Safety of Function. The safety of function mainly refers to the packing of pollution-free, non-toxic and effective protection of ceramic products. The way of Online purchase shows all the information of the ceramic product on the Internet, which brings a digital packaging. Therefore, what is important is that online ceramic products packaging is safety and protective. Ceramics are vulnerable and fragile products, and it need to move away for numerous times that the ceramic products are delivered to the consumer. Thus online ceramic packaging should follow the principle of "function is the first", so that it can protect the porcelain and reduce the risk of breakage. In the aspect of packaging structure, the product should be stabilized and the gap in the package should be minimized to ensure the product safety. Further more, one of the important indicators to measure the safety of packaging is that the material have no pollution and no poison, which need to be incorporated into the functional considerations.

To Design Simple Form. On one hand, the advertisement of ceramic products are displayed through the forms of digital media on the Internet, such as pictures, video, interactive animation and other digital packaging. Thus consumers can understand all of the information of goods rather than touch the packaging directly. Therefore, it is useless to add to beautification, display, promotion and other function of added value on packaging. On the other hand, Since the complicated "inside three, outer three" luxurious packaging is no longer used after opening the wrapping off the gift apart, will increase the burden of the environment and the cost of sales, ceramic packaging design should follow the principle of simple form, get rid of the tedious to simple. Since luxurious packaging is no longer used after being opened, it will increase the burden on the environment and the selling cost. Besides that, Ceramic packaging is divided into logistics and commodity packing, and online sellers can distribution simple transport packaging for customers who buy ceramics for themselves, so as to satisfy the consumer's requirements both functionally and economically, meanwhile, to simplify the printing and processing times so as to solve the problem of environmental protection.

To Strengthen Visual Identification. One of the best ways that solve the problem of logistics packaging design is to strengthen the visual recognition of packaging, which is the method to simplify the packaging to satisfy the need of green design. At present, while the online ceramics are transported to the consumer's home, the ceramic products are layers of parcels, which is difficult to identify commodity information. If the product attributes and logistics information are printed on 
the packing box, and the color, pattern, text and logo of the product is designed for further standardization in terms of the characteristics of the product, it is very convenient for the courier and consumer, so as to establish digital and effective package management system and meet the needs of green design.

To Use Green Materials. The realization of green design of online ceramic packaging can be embodied not only in its usage but also in the selection of materials. Material itself must be harmless to the human body, no pollution to the ecological environment, and easy to recycle, or can be regenerated and disposed to decrease the environmental harm. Firstly, to select the materials which are degradable and corrodible during the whole life of products. For example, we can select molded pulp material as the main lining of ceramic packaging in order to recycling and degradation. Secondly, to select the modern packaging materials which are not harmful to human health. Thirdly, to select single material. We can make integration of outer packaging and lining cushioning material, highlight the material itself and reinforce the quality of environment of material. Lastly, we should minimize the use of materials and improve the recycling of packaging, and to develop packaging materials technology, garbage collection and processing technology and new packaging.

\section{Summary}

For ceramic green packaging of online shopping, we should achieve a goal that ensure the maximum of natural resources, the formation of a minimum number of waste and minimum environmental pollution. From the packaging design, the methods of green design of online shopping packaging ceramic products must be considered in some aspects, such as the packaging structure, function, form, visual identity and materials. Only in this way can we promote the packaging industry effectively to get the positive cycle and ensure the maximum savings of global resources.

\section{References}

[1]Heping Zhu, Research on the theory and application of modern packaging design, edited by People's Press, Beijing, 2008.

[2]Haisheng Ke, Packaging Engineering, J.2013(8), pp. 120-123.

[3]Wenyao Zhan, Ecological Economy, 2014 (2), pp. 160-164.

[4]Guiyu Zheng, Modern Business, 2008 ( 23 ) , pp. 180-181.

[5] Peipei Wu, Lanping Xu, Packaging Engineering, 2015 ( 1 ) , pp. 94-96. 